\title{
O MERCADO DE CRÉDITOS DE CARBONO E A POSSIBILIDADE DE FOMENTO MEDIANTE INCENTIVOS FISCAIS
}

\author{
THE CARBON CREDIT MARKET AND THE POSSIBILITY OF \\ PROMOTING IT THROUGH TAX INCENTIVES
}

\author{
André Folloni* \\ Vitor José Borghi* ${ }^{* *}$
}

\begin{abstract}
Resumo: O artigo examina a possibilidade de fomentar o mercado de créditos de carbono por meio de iniciativas do poder público, em especial, pela concessão de incentivos fiscais. Para tanto, trata do Mecanismo de Desenvolvimento Limpo (MDL) e do contexto em que foi criado, elucidando a estrutura e requisitos de um projeto de MDL. Dá-se enfoque aos aspectos tributários do mercado de crédito de carbono, analisando sua natureza jurídica de bem intangível, sua transferência de titularidade por cessão e os tributos potencialmente aplicáveis às transferências onerosas de créditos de carbono. Por fim, examina os elementos do Direito Tributário aplicáveis para a proteção ao meio ambiente, mormente, a função extrafiscal do tributo, concluindo pela possibilidade de isenção tributária para o mercado de créditos de carbono, por estar em consonância com as diretrizes constitucionais de proteção ambiental e desenvolvimento sustentável.
\end{abstract}

Palavras-chave: Créditos de carbono; Desenvolvimento; Incentivos Fiscais; Intervenção do Estado; Tributação.

\begin{abstract}
The article studies the possibility of promoting the carbon credit market through government initiatives, in particular by granting tax incentives. Therefore, it explores the Clean Development Mechanism (CDM) and the context it was created, elucidating the structure and requirements of a CDM project. It approaches the tax aspects of the carbon credit market, analyzing its legal nature as an intangible good, its assignment for title transfer and potentially applicable taxes to onerous transfer of carbon credits. Finally, it examines the elements from tax law applicable to environmental protection, especially the extrafiscal function of the tribute, concluding for the possibility of tax exemption for carbon credits market, to be consistent with the constitutional guidelines for environmental protection and sustainable development.
\end{abstract}

Keywords: Carbon credits; Tax incentives; State intervention; Taxation; Development.

\footnotetext{
* Doutor em Direito do Estado pela UFPR. Professor do PPGD (Mestrado e Doutorado) da PUCPR. Email: folloni.andre@pucpr.br.

** Mestre em Direito pela Pontifícia Universidade Católica do Paraná. Especialista em Direito Processual Civil Contemporâneo pela mesma instituição. Graduado em Direito pela Universidade Estadual de Maringá e em Tecnologia em Agronegócios pelo Centro de Ensino Superior de Maringá. Membro do Núcleo de Pesquisas em Políticas Públicas e Desenvolvimento Humano da Pontifícia Universidade Católica do Paraná. Advogado e Parecerista. Sócio do escritório Borghi \& Kotsifas - Advogados Associados. E-mail: vitor_borghi@hotmail.com.
} 
O mercado de créditos de carbono e a possibilidade de fomento mediante incentivos fiscais

\section{INTRODUÇÃO}

O presente artigo examina a possibilidade de fomento do mercado de créditos de carbono por meio de atuação estatal materializada em incentivos tributários. O objetivo é descobrir se é permitido e aconselhável que o poder público use de ferramentas tributárias para fomentar esse mercado.

Para atingir esse objetivo, o artigo contextualiza, primeiramente, as questões ambientais relevantes. Em seguida, examina os mecanismos de desenvolvimento limpo, a que se segue um estudo da tributação aplicável aos créditos de carbono. Adiante, são analisadas as funções da tributação, em especial a extrafiscalidade, a possibilidade de o Poder Público estimular o mercado de créditos de carbono, e os eventuais impactos que tal medida poderia produzir na economia e no meio ambiente, para concluir pela sustentabilidade da medida.

\section{A QUESTÃO AMBIENTAL}

Embora a busca pelo crescimento dos países não seja algo recente, a degradação ambiental por ela provocada vem, nas últimas décadas, atingindo índices relevantes (CASARA, 2009, p. 23). Essa agressão aos bens da natureza e à própria teia da vida é um dos males que vem propagando o "pânico universal" que paira sobre a humanidade neste início de século. Isso porque acredita-se que os elevados níveis de emissão de gases de efeito estufa dos países desenvolvidos, aliados ao crescimento desenfreado e não sustentável de certos países em desenvolvimento, poderão agravar o problema das mudanças climáticas, tornando-o cada vez mais recorrente nas discussões e negociações internacionais (MILARÊ, 2007, p. 61).

Gabriel Sister (2008, p.1) explica que o efeito estufa é formado por gases que constroem uma espécie de película entre a atmosfera terrestre e o espaço, impossibilitando a reflexão da irradiação solar que provoca o aquecimento global. Caso o aquecimento global continue, estima-se que as mortes relacionadas a tal evento deverão dobrar em apenas 25 anos, atingindo algo em torno de trezentas mil pessoas. $\mathrm{O}$ nível dos oceanos deverá subir mais de seis metros e a estimativa é que mais de um milhão de espécies deverão entrar em extinção até o ano de 2050. 
Nesse contexto, a partir da década de 1980 intensificou-se uma conscientização global de que as ações antrópicas geram perigo iminente para a continuidade de um meio ambiente ecologicamente equilibrado, de modo que as nações começaram a discutir maneiras de enfrentar os problemas que poderiam vir a surgir (SISTER, 2008, p. 3). Como resultado, em 1998, foi instituído o Protocolo de Quioto, que é caracterizado como um adendo à Convenção Quadro das Nações Unidas para a Mudança do Clima, e “[...] estabeleceu como meta para 38 países industrializados reduzir as emissões dos gases que contribuem para o efeito em 5,2\%, no período de 2008 até 2012, em relação aos níveis existentes em 1990” (SEIFFERT, 2009, p. 36).

Para viabilizar o cumprimento das metas e possibilitar a manutenção do desenvolvimento, o mesmo Protocolo criou mecanismos de flexibilização, dentre eles, o mecanismo de desenvolvimento limpo, objeto de estudo deste trabalho. Este mecanismo consiste em uma forma subsidiária de cumprimento das metas de redução da emissão de gases de efeito estufa, onde cada tonelada métrica de carbono reduzida ou retirada da atmosfera por um país em desenvolvimento poderá ser negociada com países com meta de redução, o que cria um novo atrativo para a redução das emissões globais (SISTER, 2009, p. 13).

Por sua extensão territorial e ampla disponibilidade de recursos naturais, o Brasil se encontra em posição privilegiada para o cultivo de mecanismos de desenvolvimento limpo, tendo capacidade para se transformar em uma potência neste mercado. Por essa razão, o presente trabalho se restringe a abordar o crédito de carbono e a tributação concernente ao mercado brasileiro, avaliando a importância que este mecanismo apresenta para o desenvolvimento nacional e para a proteção ambiental, sendo que os efeitos desta última serão sentidos por todo o planeta.

Pelo artigo 225 da Constituição Federal, todos os brasileiros têm direito ao meio ambiente ecologicamente equilibrado, tratando-se de bem de uso comum do povo e essencial à qualidade de vida, impondo o dever de preservá-lo e defendê-lo ao Poder Público e à coletividade. A mesma Constituição, em seu artigo 170, dispõe que a ordem econômica deve se pautar pela defesa do meio ambiente, tratando diferenciadamente os sujeitos, conforme os impactos ambientais causados pela atividade.

Nessa perspectiva fica clara a ideia constitucional de desenvolvimento. Como ressaltam Augusto Resende e Emerson Gabardo (2013), o direito ao desenvolvimento está intimamente jungido à concretização da dignidade da pessoa 
O mercado de créditos de carbono e a possibilidade de fomento mediante incentivos fiscais

humana e à defesa do meio ambiente, de forma que se deve buscar o desenvolvimento com o mínimo de impactos negativos na natureza, promovendo, assim, o desenvolvimento sustentável.

\section{MECANISMO DE DESENVOLVIMENTO LIMPO}

Em 1990, foi criada a Convenção-Quadro das Nações Unidas para Mudança do Clima. A Convenção-Quadro foi aberta para adesões em 1992 durante a Cúpula da Terra, realizada no Rio de Janeiro. Um dos objetivos foi estabelecer as diretrizes e condições para a estabilização dos níveis de gases causadores de efeito estufa (GEE) na atmosfera (CASARA, 2009, p. 75). Na oportunidade, em atenção ao princípio das responsabilidades comuns, porém diferenciadas, ficou combinado que os países desenvolvidos deveriam tomar a iniciativa no combate à mudança do clima e seus efeitos. Para tanto, deveriam retornar suas emissões de gases de efeito estufa, por volta do ano 2000, aos níveis anteriores a 1990 (SABBAG, 2009, p. 33).

César Modena e Deise Brancher (2012, p. 153) explicam que o princípio da responsabilidade comum, mas diferenciada, surgiu também por pressão dos países em desenvolvimento, e propõe que todos os Estados sejam solidários e unam esforços em prol da proteção ambiental, mas recomenda que a responsabilidade de cada nação seja fixada pelo grau de degradação que tenha causado. Acontece que, como lembra Mônica Damasceno (2007, p. 42), a Convenção do Clima não é considerada um tratado impositivo, com normas e regras cogentes. Tratar-se-ia de uma soft law, que necessita de outros meios para regulamentá-la. Por esse motivo, em dezembro de 1997, foi criado Protocolo de Quioto, aberto para assinaturas em 16.03.1998, e que entrou em vigor em 16.02.2005.

Para que entrasse em vigor era necessário que o acordo fosse ratificado por, no mínimo, 55 Partes da Convenção-Quadro, desde que correspondessem por, pelo menos, 55\% das emissões totais de dióxido de carbono (CASARA, 2009, p.79). As partes signatárias da Convenção foram divididas em três grupos: Países do anexo I; Países do anexo II; e Países em desenvolvimento (DAMASCENO, 2007, p. 46).

Os países pertencentes ao Anexo I são os países industrializados membros da Organização para o Crescimento e Desenvolvimento Econômico, exceto México e Coréia do Sul, com grandes níveis de emissão de gases de efeito estufa e condições 
financeiras e tecnológicas para atingir as reduções determinadas. O segundo bloco, denominado Anexo II, é formado pelos países industrializados com a obrigação de ajudar com recursos financeiros e tecnológicos os países em desenvolvimento. Já o Anexo III é formado pelos países em desenvolvimento que, apesar de não possuírem metas de redução, podem auxiliar os países desenvolvidos no cumprido de suas metas (GODOY; PAMPLONA, 2007).

Para viabilizar o alcance das metas traçadas, possibilitou-se às partes mencionadas no Anexo I o cumprimento de forma flexível. Isto é, em vez de reduzirem as emissões apenas em seu próprio território, também podem escolher outros meios de redução por meio de mecanismos de flexibilização previstos no próprio Protocolo de Quioto. Esses mecanismos são a implementação conjunta, o Comércio de Emissões e o Mecanismo de Desenvolvimento Limpo.

Para o Brasil, o Mecanismo de Desenvolvimento Limpo apresenta maior relevância, por ser o único em que um país em desenvolvimento pode participar na contabilização do cumprimento de redução de emissões de GEE assumidas pelos países desenvolvidos (LORENZONI, 2009, p. 26-27). Esse mecanismo consiste em uma forma subsidiária de cumprimento das metas de redução da emissão de gases de efeito estufa, no qual cada tonelada métrica de carbono reduzida ou retirada da atmosfera por um país em desenvolvimento poderá ser negociada com países com meta de redução, o que cria um novo atrativo para a redução das emissões globais (SISTER, 2008, p. 13).

As atividades de projeto de MDL são aquelas integrantes de um empreendimento que tenha por objetivo a redução de emissões de GEE ou a remoção de $\mathrm{CO}_{2}$ da atmosfera. As atividades dos projetos necessariamente deverão estar relacionadas a tipos de gases de efeito estufa, determinados no Protocolo de Quioto, e aos setores de atividades responsáveis pela maior parte de emissões, conforme previsto no Anexo A do Protocolo (CASARA, 2009, p. 101). Dessa forma, além de auxiliar os países desenvolvidos na busca por suas metas de redução, o MDL também tem por objetivo proporcionar assistência aos países em desenvolvimento, para que alcancem o desenvolvimento sustentável e contribuam com a mitigação do aquecimento global (LORENZONI, 2009, p. 27).

O projeto de MDL deverá apresentar alguns requisitos de elegibilidade, com o objetivo de maximizar seus benefícios socioambientais em uma perspectiva mais holística. Aqui estão relacionadas grandes preocupações em assegurar que a 
O mercado de créditos de carbono e a possibilidade de fomento mediante incentivos fiscais

implantação destes projetos contribua de forma efetiva para garantir a sustentabilidade do país hospedeiro e redução de emissão de gases de efeito estufa a nível global (SEIFFERT, 2009, p. 81). Os requisitos estão dispostos no artigo 12, § 5. ${ }^{\circ}$, do Protocolo de Quioto: voluntariedade, benefícios reais e adicionalidade (CASARA, 2009, p. 104).

Por se tratar de um mecanismo que permite que a redução na emissão de gases de efeito estufa em um país de desenvolvimento seja aproveitada para o abatimento da meta de redução de um país desenvolvido, a concepção das regras envolvidas na elaboração de atividades de projeto de MDL foi feita de forma rígida e estanque, com o intuito de zelar pela confiabilidade do sistema no que se refere ao balanço global de reduções (MAGALHÃES,; MOZZER; SHELLARD, 2007, p. 148).

Por fim, todos os projetos de MDL devem respeitar as especificações trazidas nos Acordos de Marraqueche e as demais decisões tomadas no âmbito da COP/MOP (CASARA, 2009, p. 113-114). Portanto, as Reduções Certificadas de Emissões (RCEs) apenas serão expedidas após cumpridas as seguintes fases: (1) Elaboração do Documento de Concepção do Projeto; (2) Validação; (3) Aprovação; (4) Registro; (5) Monitoramento; (6) Verificação/Certificação. A sétima fase é a emissão das RCEs.

Em geral, projetos de MDL podem ser projetos de sumidouros de gás de efeito estufa e projetos de redução de emissões. No entanto, importa apenas que a sua implantação induza à redução dos níveis de emissão de GEEs no processo produtivo ou à imobilização (remoção) desses gases da atmosfera (SEIFFERT, 2009, p. 93). Para a aferição, sempre devem ser realizadas análises comparativas do estado da arte de projetos similares no setor, ou seja, se o processo fosse conduzido na forma tradicional de implantação.

\section{MERCADO DE CRÉDITOS DE CARBONO}

Quanto ao mercado de créditos de carbono, embora ainda careça de regulamentação, entende-se que engloba qualquer transação mercantil envolvendo os créditos de carbono. Pode ser institucional, organizado sob a forma de um mercado de balcão ou por um negócio particular varejista (LORENZONI, 2009, p. 73). Dessa forma, as empresas poluidoras podem adquirir em bolsa ou diretamente das empresas 
empreendedoras as toneladas de carbono sequestradas ou não emitidas através das RCEs - mais especificamente, por meio de contratos de cessão de RCEs.

Já a circulação de reduções certificadas de emissão pode ocorrer após a sua emissão e antes de sua distribuição pelo Conselho Executivo, no que é conhecido como "mercado à vista primário de carbono", ou após a sua distribuição, caracterizando o “mercado à vista secundário". Ainda, é possível a negociação de promessas de créditos de carbono antes ou durante o ciclo do projeto de MDL, formando o chamado mercado a termo de reduções ainda não certificadas de emissão (SABBAG, 2009, p. 94).

Como já mencionado, são diversas as formas de negociação de crédito de carbono. Todavia, a mais usual é o uso das bolsas de valores. No Brasil, a Bolsa de Mercadorias e Futuros - BM\&F coordena o Banco de Projetos de MDL que tenham sido validados por uma Entidade Operacional Designada (EOD) e que tenham boa expectativa de geração de créditos de carbono no futuro, assim como projetos cuja concepção esteja parcialmente estruturada (LIMIRO, 2009, p. 129).

Na BM\&F/BOVESPA, o crédito de carbono pode ser negociado no mercado à vista, por meio do sistema eletrônico de leilões. Também é possível a criação de módulo específico para negociação a termo de créditos de carbono. Os leilões podem ser públicos e privados, nos quais é garantido o anonimato dos participantes, e cada leilão realizado é modelado de acordo com as características da oferta. As regras de negociação de cada leilão são divulgadas por meio de editais disponibilizados no sítio eletrônico da BM\&F/BOVESPA antes da data de realização de cada leilão (BM\&F BOVESPA, 2007).

\section{INCENTIVOS FISCAIS NO MERCADO DE CRÉDITOS DE CARBONO}

Compreendidos, em linhas gerais, os negócios jurídicos que envolvem os créditos de carbono, passamos a examinar a tributação que incide sobre essas atividades.

No que concerne ao Mecanismo de Desenvolvimento Limpo, instituto recente, é preciso reconhecer que não existe, até o momento, legislação específica que determine o tratamento tributário a ser aplicado nas relações de mercado de RCEs (MENDONÇA; ANTUNES, 2010, p. 5).

O vazio normativo alcança até mesmo a classificação da natureza jurídica do crédito de carbono. Essa indefinição gera grande insegurança para o mercado, 
O mercado de créditos de carbono e a possibilidade de fomento mediante incentivos fiscais

especialmente quanto à forma de negociação e tributação desses créditos. Por esse motivo, Bruno Sabbag (2009, p. 89) afirma ser essencial que a doutrina assuma esse papel, até que advenha legislação específica neste sentido no Brasil. E, realmente, a partir da análise da natureza jurídica da RCE e de seu mercado, é possível procurar compreender que fatos jurídicos estariam sujeitos a incidência tributária, levando-se em consideração as regras gerais já existentes.

Com efeito, o estudo desenvolvido por Gabriel Sister (2008, p. 48-51), a partir da classificação de bens sedimentada pela legislação e doutrina pátria, concluiu que as RCEs, enquanto direitos sem existência tangível, mas com valor econômico, enquadram-se com perfeição na acepção de bens intangíveis. De fato, essa parece ser a melhor classificação. Contudo, há quem discorde dessa classificação e tenha tentado defini-la como "serviço", "valor mobiliário" ou então "commodity ambiental".

A definição da natureza jurídica das RCEs como prestação de serviço ganhou força em razão da Circular n ${ }^{\circ}$ 3.291, emitida em 8.9.2006 pelo Banco Central do Brasil (“Circular BACEN n $3.291 / 05$ ”), que prevê expressamente um código para a realização de operações de câmbio relativas a operações de mercado de carbono, cuja natureza é classificada como "Serviços Diversos - Créditos de Carbono 29/(NR) 45500. (PLAZA; SANTOS, 2009, p. 2574). No entanto, como afirma Fernando Gonçalves (2007, p. 258), esse posicionamento não observa que, para existir um serviço, também deve existir uma obrigação de fazer, o que não acontece quando a obrigação é de dar alguma coisa a alguém, como ocorre com as RCEs mediante a sua cessão ao adquirente. Para complementar, o autor ressalta que a diferença já foi analisada pelo Plenário do Supremo Tribunal Federal, quando concluiu pela não incidência do Imposto sobre Serviços (ISS) na locação de bens móveis ao julgar o Recurso Extraordinário n. 116.121-3-SP.

Por sua vez, a possiblidade de enquadrar a RCE como valor mobiliário foi suscitada pelos Projetos de Lei n. 3552/2004 e 493/2007 de autoria dos então Deputados Federais Eduardo Paes e Eduardo Gomes, respectivamente. Até o momento, nenhuma lei com tal propósito foi sancionada.

É preciso registrar que, apesar dos mencionados Projetos de Lei, não se considera adequada a classificação da RCE como valor mobiliário. Isso porque, no Brasil, o rol de valores mobiliários está taxativamente indicado no artigo $2^{\circ}$ da Lei 6.385/76, não sendo possível o enquadramento da RCE em nenhuma das hipóteses 
previstas na referida legislação. Nesse sentido, ainda é válido destacar que a Comissão de Valores Mobiliários (2009), emitiu parecer sobre o tema, onde se concluiu que os Créditos de Carbono não são valores mobiliários, mas sim meros ativos cuja comercialização pode ocorrer para o cumprimento de metas de redução de emissão de carbono ou com o objetivo de investimento.

Por fim, a acepção do crédito de carbono como commodity ambiental também não parece adequada. Como afirma Antonio Lorenzoni Neto (2009, p. 42), no âmbito do crédito de carbono, o ar não pode ser concebido como commodity ambiental, uma vez que o destinatário final da RCE é quem necessita reduzir sua cota de poluentes emitidos. Assim, não seria o ar que se identificaria como produto da espécie commodity ambiental, mas, sim, o controle de emissão de poluentes, mensurado, nesse caso, em $\mathrm{tCO}_{2}$ /ano. Não obstante, Fernando Gonçalves (2007,p. 259) afirma que, para ser commodity, a RCE necessitaria, por consequência, ser mercadoria, o que, em seu conceito clássico, abrange somente os bens móveis, corpóreos, tangíveis ou semoventes inseridos nas atividades dos mercadores com a necessidade de mudança de titularidade, características não vislumbradas no crédito de carbono.

Diante disso, enquanto a Lei não define a classificação da natureza jurídica do crédito de carbono, é necessário estudá-lo pelo posicionamento que parece mais adequado, qual seja, o de que se trata de bem incorpóreo ou intangível. Uma vez aceita essa como a natureza jurídica do bem, também se torna possível definir a natureza jurídica de sua transferência onerosa como a de cessão: “[...] o crédito, como integrante de um patrimônio, possui um valor de comércio. Trata-se, sem dúvida, de uma alienação. Quando, no direito, a alienação tem por fim bens imateriais, toma o nome de cessão" (VENOSA, 2011, p. 150). Sujeita-se, então, ao mesmo tratamento legal tributário conferido às cessões de bens intangíveis ou cessões de direitos (SISTER, 2008, p. 51).

Em seu estudo sobre o tema, Gabriel Sister (2008, p. 48-51) concluiu pela provável incidência dos seguintes tributos federais: i) Imposto de Renda; ii) Contribuição ao Programa de Integração Social e de Formação do Patrimônio do Servidor Público (PIS/Pasep); iii) Contribuição para o Financiamento da Seguridade Social (Cofins); iv) Contribuição Social sobre o Lucro Líquido (CSLL); v) IOFCâmbio, quando ocorrer a cessão entre pessoas de diferentes jurisdições, com a consequente troca de moedas. 
O mercado de créditos de carbono e a possibilidade de fomento mediante incentivos fiscais

Também merece destaque o posicionamento adotado pela Receita Federal. Em 10 de março de 2008, foi submetida à $9^{\text {a }}$ Região Fiscal da Receita Federal a consulta n. 59, questionando, no que tange à cessão de direitos relativos a créditos de carbono para o exterior: a) a incidência e alíquota do Imposto sobre a Renda da Pessoa Jurídica; b) a incidência de PIS/Pasep; e c) a incidência de Cofins.

Comentando o caso, Arnaldo Godoy (2012) explica que a consulente é sociedade anônima de capital fechado, com sede em Santa Catarina e que atua no ramo de comercialização de energia elétrica. Pretendendo gerar créditos de carbono, a consulente teria projetado e construído pequena central hidrelétrica a fio d'água, projeto que desestimularia o uso de carvão mineral, fonte prioritária de energia da região. Diante disso, a Comissão Interministerial de Mudança do Clima homologou 133.992 (cento e trinta e três mil, novecentos e noventa e dois) créditos, que foram cedidos a uma empresa japonesa pela quantia de $€ 2.277,864$ (dois milhões, duzentos e setenta e sete mil, oitocentos e sessenta e quatro euros).

Ao levar o caso ao conhecimento da Receita Federal, a empresa interessada afirmou a impossibilidade de incidência das contribuições PIS/PASEP e Cofins, tendo em vista o disposto no inciso I, do parágrafo $2^{\circ}$, do artigo 149 da Constituição Federal de 1988, que dispõe que as contribuições sociais e de intervenção no domínio econômico não incidem sobre as receitas decorrentes de exportação. Além disso, a empresa também advogou pela isenção ao PIS/Pasep/Cofins prevista na Medida Provisória 2.158-35 sobre as receitas decorrentes de serviços prestados a pessoa física ou jurídica residente ou domiciliada no exterior, cujo pagamento represente ingresso de divisas. Já quanto ao Imposto sobre a Renda da Pessoa Jurídica, argumentou a interessada que a cessão do crédito deveria ser entendida como comercialização de energia, tratando-se de receita operacional da empresa, de forma que a alíquota aplicável ao caso seria na quadra de 8\%, nos termos do caput do art. 518 do Regulamento do Imposto de Renda, Decreto $n^{\circ} 3.000$, de 26 de março de 1999 (GODOI, 2012).

Em resposta à consulta, a Receita Federal concluiu que a cessão para o exterior de direitos relativos a créditos de carbono está sujeita ao percentual de $32 \%$ para fins de apuração da base de cálculo do Imposto de Renda de Pessoa Jurídica sob o regime de lucro presumido. Quanto ao PIS/PASEP e à Cofins, a Receita Federal declarou a sua isenção na receita relativa à cessão para o exterior de direitos relativos a 
créditos de carbono, cujo pagamento represente ingresso de divisas, nos termos do inciso III e do parágrafo $1^{\circ}$ do art. 14, da Medida Provisória 2.158-35/2001 (BRASIL, 2008).

Primeiramente, nota-se que, apesar da Receita Federal definir a comercialização do crédito de carbono como cessão, o dispositivo utilizado para fundamentar a isenção do PIS/Pasep e Cofins é voltado para a prestação de serviços, o que revela, no mínimo, um contrassenso na análise feita pelo órgão. Na realidade, mais adequado ao caso seria o reconhecimento da imunidade de tais tributos para o caso em decorrência do estabelecido no art. 149, parágrafo $2^{\circ}$, inciso I da Constituição Federal de 1988 .

Não obstante, o caso narrado é importante por duas razões primordiais: a primeira é pelo endosso à corrente doutrinária que reconhece a transferência do crédito de carbono como cessão, e a segunda por demonstrar o ônus exacerbado imposto ao contribuinte ao negociar no mercado de créditos de carbono.

A incidência de uma carga tributária elevada sobre a comercialização do crédito de carbono pode acabar por desestimular o investimento da iniciativa privada nesse mercado e, por consequência, o seu desenvolvimento. Sob esse ponto de vista, é razoável cogitar-se de maneiras de fomentar esse mercado por meio de desonerações fiscais, tornando-o mais atrativo para os investidores e contribuindo com a redução de emissões de gases de efeito estufa. Afinal, os tributos são largamente utilizados com o intuito de interferir na economia privada, estimulando atividades, setores econômicos ou regiões, desestimulando o consumo de certos bens, produzindo, assim, os mais diversos efeitos na economia. A essa função intervencionista do tributo dá-se o nome de extrafiscalidade (MACHADO, 2011, p. 68).

De um modo geral, a extrafiscalidade pode ser verificada em duas ocasiões: nos agravamentos fiscais, através do aumento da carga tributária, o que representa desestímulo econômico à adoção de condutas lícitas, porém indesejáveis; e nos benefícios fiscais, pela isenção, redução ou, até mesmo, manutenção da carga tributária em situações gerais de aumento, o que representa estímulo econômico à adoção de condutas permitidas, não obrigatórias mas desejáveis (FOLLONI, 2014, p. 207).

Em matéria ambiental, Paulo Caliendo (2013, p. 188) aponta dois grandes grupos de soluções tributárias utilizadas com o intuito de promover um meio ambiente ecologicamente equilibrado, são eles, a imposição de tributos ambientais que consiste 
O mercado de créditos de carbono e a possibilidade de fomento mediante incentivos fiscais

em estabelecer um padrão de conduta e a exigência da internalização do custo das externalidades, tornando a atividade mais cara, e a criação de incentivos à produção sustentável, como um tipo de solução positiva que pretende induzir a tomada de decisões sustentáveis pela indicação de benefícios.

A preocupação com o meio ambiente no mundo fez com que diversos países, principalmente os europeus, adotassem a chamada "tributação ecológica" como meio de despertar a importância da consciência ambiental entre seus cidadãos, a fim de promover um meio ambiente sustentável. No Brasil, por meio da edição da Emenda Constitucional $n^{\circ} 42$, de 19 de dezembro de 2003, ficou estabelecido que, dentre outros princípios, a ordem econômica deve sagrar a defesa do meio ambiente mediante tratamento diferenciado conforme o impacto ambiental causado (SISTER, 2008, p. 6768).

Henrique Ricci (2014, p. 61) pontua que o direito tributário é uma das ferramentas de atuação nas externalidades resultantes das atividades privadas que tem repercussões na coletividade em geral. No caso tratado, os créditos de carbono provocam externalidades positivas na sociedade em geral, ao reduzir o volume de emissões de gases tóxicos e colaborar com a construção de um meio ambiente ecologicamente equilibrado.

Dessa forma, a tributação com caráter ambiental pretende ser um instrumento cuja finalidade é alcançar a eficiência do sistema, proporcionando o equilíbrio voltado ao desenvolvimento sem se esquecer do meio ambiente (MENDONÇA; ANTUNES, 2010, p. 10).

Com efeito, o desenvolvimento sustentável não se pratica apenas com a monetarização dos recursos ambientais ou com sua compensação econômica, mas pela execução de políticas efetivas de prevenção e redução de eventuais danos ao meio ambiente, bem como recuperação daquilo que já foi degradado (AMARAL, 2007, p. 50). No entanto, também parece óbvio que as isenções, subsídios, subvenções, reduções de alíquotas e bases de cálculo são sinais de desenvolvimento com a minoração da carga tributária e fomentam desenvolvimento sustentável (TRENNEPOHL, 2011, p. 130).

Frisando a importância do incentivo estatal para a defesa eficiente do meio ambiente, Carolina Costa de Aguiar e Flávia Trentini (2014, p. 70) observam que as instituições de controle estatal cometem falhas na proteção ambiental, apresentando deficiências relativas à efetiva fiscalização e sanção. Por isso, as autoras consideram que 
é necessário contar com mecanismos de incentivo que induzam práticas mais adequadas do ponto de vista ambiental.

Assim, é fundamental que as atividades não-poluidoras sejam incentivadas por meio de instrumentos tributários e econômicos em detrimento das poluidoras, motivando os agentes poluidores a adotarem novas e adequadas tecnologias limpas, para reduzirem os custos em seus processos de produção. Caso seja de fato implementada, essa política provocará a diminuição dos custos sociais com a poluição ambiental, aumentando o nível de bem-estar coletivo e produzindo, via de consequência, benefícios em termos de saúde pública (AMARAL, 2007, p. 51).

O artigo 12, inciso $8^{\circ}$, do Protocolo de Quioto, suscita a criação de dois tributos com incidência sobre o mercado de carbonos no âmbito internacional, sendo um para cobrir as despesas administrativas e outro para assistir aos países em desenvolvimento signatários do Protocolo que sejam vulneráveis aos efeitos adversos das mudanças climáticas para fazer face aos custos de adaptação. Como lembram SABBAG e MACHADO FILHO (2008, p. 818) este segundo tributo foi definido em $2 \%$ (dois por cento) da quantidade total de RCEs emitidas para o projeto de MDL, contudo, os projetos hospedados nos países menos desenvolvidos foram isentos do seu pagamento pelo art. 15 da Decisão 17/CP.7.

A exemplo do que prevê o Protocolo de Quioto, também deve o Brasil isentar de tributos as operações de créditos de carbono. Como ensina Roque Antonio Carrazza (2004, p. 780), quem cria o tributo pode, por igual modo, aumentá-lo, diminuílo ou até suprimi-lo, com base na não-tributação pura e simples. Da mesma forma, é possível a isenção de tributos, dependendo, apenas, de uma decisão política que, via de regra, é tomada pela própria entidade tributante. Nessa linha, leciona o autor que "[...] a isenção tributária encontra fundamento na falta de capacidade econômica do beneficiário ou nos objetivos de utilidade geral ou de oportunidade política que o Estado pretende venham alcançados" (CARRAZZA, 2004, p. 782).

Com efeito, três Projetos de Lei já foram criados com tal intuito, a saber: $n$. 4.425/2004, 494/2007 e 1.657/2007. Os três projetos previam a exclusão do lucro tributável pelo IRPJ e pela CSLL, bem como a isenção de PIS e Cofins sobre as receitas decorrentes da cessão de créditos de carbono (SABBAG; MACHADO FILHO, 2008, p. 819-820). No entanto, todos estes Projetos de Lei foram arquivados pela Câmara dos Deputados com fundamento no artigo 105 do Regimento Interno ${ }^{1}$. Portanto, a despeito 
O mercado de créditos de carbono e a possibilidade de fomento mediante incentivos fiscais

da boa vontade de alguns parlamentares na concessão de benefícios fiscais para a promoção do mercado do mercado de créditos de carbono, o que se tem até o momento, é aplicação total da carga tributária às operações deste mercado ${ }^{2}$.

A consequência lógica dessa situação é o aumento da arrecadação pelos cofres públicos em detrimento do desenvolvimento do mercado de créditos de carbono. Essa conjuntura contraria o verdadeiro intuito das iniciativas nacionais e internacionais referentes à Convenção e ao Protocolo de Quioto, que, de acordo com Sabbag e Machado Filho, “[...] jamais tiveram em sua origem uma natureza arrecadatória, mas sim de proteção ambiental que visa a garantir a sobrevivência humana no planeta por meio do desenvolvimento sustentável e da exploração equilibrada dos recursos naturais" (SABBAG; MACHADO FILHO, 2008, p. 821).

A adoção de instrumentos tributários de isenção pode, através da extrafiscalidade, acarretar na alteração e adequação do comportamento da sociedade, promovendo o desenvolvimento sustentável e o bem-estar. Com isso, o poder público promoverá a existência digna, conforme os ditames da justiça social, a partir da defesa do meio ambiente, eliminando a atuação do intermediário, qual seja, o próprio Estado.

Embora aqui se advogue pela isenção total dos tributos incidentes sobre as operações de créditos de carbono, na prática, a decisão política de conceder ou não isenção a projetos de MDL deve ponderar os custos da poluição e de seu controle, encontrando um equilíbrio financeiro (AMARAL, 2007, p. 104). Como garante Bruno “[...] certamente, as isenções ora advogadas reduziriam os custos futuros do país, o que, a longo prazo, até mesmo beneficiaria o orçamento público" (SABBAG, 2009, p. 106)

O mercado de créditos de carbono é ainda recente e, por carecer de regulamentação, gera bastante insegurança para os investidores. Assim, a concessão de incentivos tributários para as operações de cessão onerosa e os lucros e receitas dela advindos poderá representar medida eficaz no fomento dessa atividade, atingindo objetivos do Estado e permitindo o acesso da população a um meio ambiente ecologicamente equilibrado.

\section{CONCLUSÃO}

A revolução industrial trouxe um modelo de desenvolvimento onde o crescimento econômico e a maximização da produção predominava sobre a preservação 
ambiental. Esse modelo de industrialização levou ao aumento do efeito estufa, provocado pelo acúmulo de gases poluentes. Esse fenômeno, conhecido por efeito estufa antrópico, é tido como o principal responsável pelo aquecimento global que estamos vivenciando.

Para reverter esse quadro, foi criada a Convenção Quadro das Nações Unidas para a Mudança do Clima, onde se buscou estabelecer diretrizes e condições para estabilizar os níveis de emissão de gases de efeito estufa. A Convenção adotou uma série de princípios para estabelecer as diretrizes que seriam seguidas, dos quais se destacam os quatro principais: princípio do desenvolvimento sustentável; princípio da precaução; princípio do poluidor-pagador; princípio das responsabilidades comuns, porém diferenciadas.

Assim, estabeleceu-se que os países desenvolvidos deveriam tomar a frente no combate ao aquecimento global. Como a Convenção-Quadro não impunha metas aos países signatários, precisou-se criar o Protocolo de Quioto, que funcionou como uma espécie de adendo à Convenção-Quadro e estabeleceu que os países desenvolvidos deveriam reduzir os níveis de emissão para níveis iguais aos de 1990.

Para reduzir os impactos na economia desses países provocados por essa verdadeira limitação ao crescimento, foram criadas formas de flexibilização das reduções, quais sejam, a Implementação Conjunta, o Comércio de Internacional de Emissões e o Mecanismo de Desenvolvimento Limpo. Conforme este último, cada tonelada métrica de carbono reduzida ou retirada da atmosfera por um país em desenvolvimento poderá ser negociada com países com meta de redução, o que torna este mecanismo muito importante para o Brasil, país com imensa extensão territorial e rico em recursos naturais.

Aceita a premissa de que o mecanismo de desenvolvimento constitui uma importante ferramenta para a tutela do meio ambiente, é razoável supor que a imposição de muitos tributos poderá inibir o desenvolvimento do mercado de créditos de carbono. Essa situação contraria as premissas constitucionais de que é função do Poder Público e da coletividade garantir, a todos, um meio ambiente equilibrado.

Efetivamente, é prerrogativa do poder público interferir na economia privada por meio da tributação, estimulando ou desestimulando determinadas atividades ou setores econômicos, conforme o interesse público vier a demandar, especialmente por meio de tributação extrafiscal, inclusive ambiental. 
O mercado de créditos de carbono e a possibilidade de fomento mediante incentivos fiscais

Nesse contexto, a concessão de incentivos fiscais ao mercado de créditos de carbono não é discrepante do conjunto dos preceitos constitucionais, por sua capacidade potencial de estimular a proteção ambiental e o desenvolvimento nacional de maneira sustentável.

\section{REFERÊNCIAS}

AMARAL, Paulo Henrique do. Direito tributário ambiental. São Paulo: Revista dos Tribunais, 2007.

BM\&F BOVESPA. Mercado de carbono. 2007. Disponível em: <http://www.bmf.com.br/bmfbovespa/pages/mbre/download/Carbono_100407_pt.pdf?I dioma=pt-br $>$. Acesso em: 12 nov.2014.

BRASIL. 9a Região Fiscal Divisão de Tributação. Solução de Consulta n. 59, de 10 de março de 2008. Diário Oficial da União, Brasília, DF, 7 abr.2008. Disponível em: <http://portal2.tcu.gov.br/portal/page/portal/TCU/comunidades/biblioteca_tcu/servi\%C 3\%A7os/normalizacao_publicacoes/REFERENCIAS.pdf>. Acesso em: 7 abr.2008.

BRASIL. Lei $\mathrm{n}^{\circ}$ 5.172, de 25 de outubro de 1966. Dispõe sobre o Sistema Tributário Nacional e institui normas gerais de direito tributário aplicáveis à União, Estados e Municípios. Diário Oficial da União, Brasília, DF, 25 out.1966. Disponível em: <http://www.planalto.gov.br/ccivil_03/leis/15172.htm>. Acesso em: 1 out. 2012.

CALIENDO, Paulo. Extrafiscalidade ambiental: instrumento de proteção ao meio ambiente equilibrado. In: BASSO, Ana Paula; ALBUQUERQUE, Armando; DEODATO, Filipe Augusto Forte de Negreiros; BELO, Manoel Alexandre Cavalcante; BRAGA, Romulo Rhem Palitot (org.). Direito e desenvolvimento sustentável: desafio e perspectivas. Curitiba: Juruá, 2013, p. 165-194. Disponível em: <http://www.paulocaliendo.com.br/Mostrar+arquivo/19-file1-art2>. Acesso em: 13 abr.2015.

CARRAZZA, Roque Antonio. Curso de direito constitucional tributário. 20. ed. São Paulo: Malheiros, 2004.

CASARA, Ana Cristina. Direito ambiental do clima e créditos de carbono. Curitiba: Juruá, 2009.

COMISSÃO DE VALORES MOBILIÁRIOS. Ata da Reunião do Colegiado no 25 de 07.07.2009.

<http://www.cvm.gov.br/decisoes/2009/20090707_R1.html>. Acesso em: 27 set.2012.

COSTA DE AGUIAR, Carolina; TRENTINI, Flavia. O papel da certificação na proteção ambiental realizada pela atividade agrária. Revista da Faculdade de Direito da UFG, v. 38, n. 2, p. 57-79, 2014. Disponível em: 
<http://www.revistas.ufg.br/index.php/revfd/article/view/23038/17968>. Acesso em: 03 jun. 2015.

DAMASCENO, Mônica. A Convenção Quadro das Nações Unidas sobre Mudança do Clima. In: SOUZA, Rafael Pereira de (coord). Aquecimento global e créditos de carbono: aspectos jurídicos e técnicos. São Paulo: QuartierLatin, 2007, p. 37-63.

FOLLONI, André. Isonomia na tributação extrafiscal. Revista Direito GV, São Paulo, v. 10, p. 201-220, 2014.

GODOY, Arnaldo Sampaio de Moraes. A incidência tributária na venda de créditos de carbono. Fórum de Direito Urbano e Ambiental FDUA, Belo Horizonte, v. 11, n. 62, mar./abr. 2012. Disponível em: <http://www.bidforum.com.br/bid/PDI0006.aspx?pdiCntd=78575>. Acesso em: 6 abr. 2015.

GODOY, Sara Gurfinkel Marques de; PAMPLONA, João Batista. O Protocolo de Kyoto e os países em desenvolvimento. Pesquisa \& Debate, São Paulo, v. 18, n. 2, p. 329-353, 2007. Disponível em: <http://www.pucsp.br/pos/ecopol/downloads/edicoes/(32)sara_gurfinkel.pdf>. Acesso em: 29 ago. 2012.

GONÇALVES, Fernando Dantas Casillo. A natureza jurídica das RCEs e seu regime jurídico tributário no Brasil. In: SOUZA, Rafael Pereira de (Coord). Aquecimento global e créditos de carbono: aspectos jurídicos e técnicos. São Paulo: Quartier Latin, 2007.

LIMIRO, Danielle. Créditos de carbono: Protocolo de Kyoto e projetos de MDL. Curitiba: Juruá, 2009.

LORENZONI, Antonio Neto. Contrato de créditos de carbono: análise crítica das mudanças climáticas. Curitiba: Juruá, 2009.

MACHADO, Hugo de Brito. Curso de direito tributário. 32. ed. São Paulo: Malheiros, 2011.

MACHADO FILHO, Haroldo; SABBAG, Bruno Kerlakian. Classificação da natureza jurídica do crédito de carbono e defesa da isenção tributária total às receitas decorrentes da cessão de créditos de carbono como forma de aprimorar o combate ao aquecimento global. In: BENJAMIN, Antonio Herman; LECEY, Eladio; CAPELLI, Silvia (Coords.). Mudanças climáticas, biodiversidade e uso sustentável da energia: Anais do $12^{\circ}$ Congresso Internacional de Direito Ambiental. São Paulo: Imprensa Oficial do Estado de São Paulo, 2008, p. 811-827.

MAGALHÃES, Danielle de Araújo; MOZZER, Gustavo Barbosa; SHELLARD, Sofia Nicolleti. Estrutura institucional do mecanismo de desenvolvimento limpo. In: SOUZA, Rafael Pereira de (Coord.). Aquecimento global e créditos de carbono: aspectos jurídicos e técnicos. São Paulo: Quartier Latin, 2007, p. 111-127. 
O mercado de créditos de carbono e a possibilidade de fomento mediante incentivos fiscais

MENDONÇA, Larissa Aparecida Martins; ANTUNES, Thiago Da Rocha. Tributação no mercado de créditos de carbono. In: V Mostra de produção científica da pósgraduação latu sensu da PUC Goiás, 5, p. 1, 2010. Disponível em: <http://www.cpgls.ucg.br/ArquivosUpload/1/File/V\%20MOSTRA\%20DE\%20PRODU O\%20CIENTIFICA/DIREITO/19-.PDF>. Acesso em: 11 abr.2015.

MILARÉ, Édis. Direito do ambiente: a gestão ambiental em foco: doutrina, jurisprudência, glossário. 5. ed. reform., atual. e ampl. São Paulo: Revista dos Tribunais, 2007.

MODENA, César Augusto; BRANCHER, Deise Salton. A formação do direito ambiental a partir das conferências de Estocolmo e Rio de Janeiro. Revista da Faculdade de Direito da UFG, v. 36, n. 1, p. 143-160, 2012. Disponível em: <http://www.revistas.ufg.br/index.php/revfd/article/view/16408/12661>. Acesso em: 3 jun. 2015.

PLAZA, Charlene Maria Coradini de Ávila; SANTOS, Nivaldo dos. Mercados de créditos de carbono voluntário e a emergência de definição legal no Brasil: aspectos tributários e políticas de incentivo. In: CONGRESSO NACIONAL DO CONPEDI, 18, 2008, São Paulo. Anais do XVIII Congresso Nacional do CONPEDI. Florianópolis: Fundação Boiteux, 2009, p. 2568-2595.

RESENDE, Augusto César Leite de; GABARDO, Emerson. A atividade administrativa de fomento na gestão integrada de resíduos sólidos em perspectiva com o desenvolvimento sustentável. A\&C - Revista de Direito Administrativo \& Constitucional, Belo Horizonte, ano 13, n. 53, 2013. Disponível em: $<$ http://bid.editoraforum.com.br/bid/PDI0006.aspx?pdiCntd=97394>. Acesso em: 13 abr. 2015.

RICCI, Henrique Cavalheiro. A tributação extrafiscal ambiental e a limitação imposta pela igualdade tributária. Curitiba, 2014. 182 f. Dissertação (Mestrado) Programa de Pós-Graduação em Direito, Pontifícia Universidade Católica do Paraná.

SABBAG, Bruno Kerlakian. O Protocolo de Quioto e seus créditos de carbono: manual jurídico brasileiro de mecanismo de desenvolvimento limpo. 2. ed. São Paulo: LTR, 2009.

SEIFFERT, Mari Elizabete Bernardini. Mercado de carbono e Protocolo de Quioto: oportunidades de negócio na busca da sustentabilidade. São Paulo: Atlas, 2009.

SISTER, Gabriel. Mercado de carbono e Protocolo de Quioto: aspectos negociais e tributação. 2. ed. Rio de Janeiro: Elsevier, 2008.

TRENNEPOHL, Terence Dorneles. Incentivos fiscais no direito ambiental. 2. ed. São Paulo: Saraiva, 2011.

VENOSA, Sílvio de Salvo. Direito civil: parte geral. 11. ed. São Paulo: Atlas, 2011. 
André Folloni Vitor José Borghi

Artigo recebido em 26 de junho de 2015 e aceito em 08 de fevereiro de 2016

1 "Finda a legislatura, arquivar-se-ão todas as proposições que tenham sido submetidas à deliberação da Câmara e ainda se encontrem em tramitação, bem como as que abram crédito suplementar, com pareceres ou sem eles, salvo as: [...]" (Regimento Interno da Câmara dos Deputados, 1989).

2 Faz-se a ressalva da imunidade prevista no art. 149, I, da Constituição Federal para Contribuições Sociais sobre receitas decorrentes de atividades de exportação. 